\title{
Fluidics in a Dual Pneumatic Ultra High-Speed Vitreous Cutter System
}

\author{
Bruno Diniz ${ }^{a, c}$ Ramiro M. Ribeiro ${ }^{a, d}$ Rodrigo B. Fernandes ${ }^{a, c}$ Jaw-Chyng Lue ${ }^{a}$ \\ Anderson G. Teixeirac Mauricio Maiac Mark S. Humayun ${ }^{\mathrm{a}}{ }^{\mathrm{a}} \mathrm{b}$ \\ ${ }^{a}$ Doheny Eye Institute, and ${ }^{b}$ Department of Ophthalmology, Keck School of Medicine, University of Southern \\ California, Los Angeles, Calif., USA; ' $D$ Department of Ophthalmology, Universidade Federal de São Paulo, São Paulo, \\ and ${ }^{\mathrm{d} D e p a r t m e n t}$ of Ophthalmology, Hospital Universitário de Curitiba - FEMPAR, Curitiba, Brazil
}

\section{Key Words}

Vitreoretinal surgery $\cdot$ Pars plana vitrectomy $\cdot$ Vitrectomy

\begin{abstract}
Background: Dual pneumatic systems use two separate air line tubes to open and close the cutter and can achieve high cut rates. The purpose of this study is to evaluate the influence of gauge size, cut rate and aspiration on the flow rate performance of ultra high-speed cutters operated with a commercially available dual pneumatic vitrectomy system. Methods: Analysis of a high-speed video was used to determine duty cycle. Flow rates from 20-, 23- and 25-gauge cutters were calculated in predetermined conditions of aspiration levels and cut rates; water and fresh porcine vitreous samples were studied. Results: For all three gauges of cutters, the duty cycle and water flow showed an inverse correlation with increasing cut rates and a direct correlation with increasing aspiration levels $(p<0.05)$. Vitreous flow rates from all gauges increased with increasing aspiration and cut rates $(p<0.05)$. Conclusion: Larger gauges of the cutters as well as higher aspiration and cut rate levels resulted in improvement of the vitreous flow rates. A good understanding of the different flow rate settings is essential for the surgeon and optimizes the safety of surgical procedures.
\end{abstract}

Copyright $\odot 2012$ S. Karger AG, Basel

\section{KARGER}

Fax +41613061234

E-Mail karger@karger.ch

www.karger.com
(C) 2012 S. Karger AG, Basel

0030-3755/13/2291-0015\$38.00/0

Accessible online at:

www.karger.com/oph

\section{Background}

Advances in instruments used for vitrectomy have been driven by the need for greater functionality and safety. Because small-gauge vitrectomy causes less ocular trauma and usually does not require sutures, it is becoming increasingly popular and is replacing standard 20 -gauge vitrectomy for many surgical indications. As sutureless vitrectomy is a trend in vitreoretinal surgery, efforts to improve the flow efficiency in these smaller format cutters are an important contribution to optimize this surgical procedure. New concepts of vitreous removal are focused on increasing cut speed, maximizing the cutting port surface and enlarging the diameter of the inner lumen of the probe $[1,2]$.

Fluidics of the vitrectomy system depends on the removed substance (balanced salt solution or vitreous), variable parameters (vacuum, cutting rate and duty cycle) and the overall probe inner lumen size [3]. The combination of these factors in conjunction with skills of the surgeon will result in a successful surgical procedure.

Duty cycle is the percentage of time that the probe port is open. Depending on the driving mechanism (pneumatic/spring, electric and dual pneumatic), different duty cycle rates are produced [4]. Some reports describe that pneumatic cutters with spring return systems have low 
flow rates according to high cut rates $[1,5,6]$; however, a recent publication has shown that higher duty cycle is associated with higher water flow but not necessarily with higher vitreous flow rates [7]. This finding is mainly related to changes in the duty cycle with increasing cut rates [8]. Dual pneumatic systems, which use two separate air lines to open and close the cutter, are able to achieve high cut rates and can modulate the duty cycle [8]. The use of ultra high-speed cutters [up to 5,000 cuts per minute $(\mathrm{CPM})]$ should increase the vitreous flow by reducing the size of the vitreous pieces and consequently reducing its viscosity and resistance to the flow inside the aspiration tube $[9,10]$.

Choosing the optimal instrumentation and settings has become increasingly challenging [11]. The current availability of 20-, 23- and 25-gauge vitrectomy systems provides surgeons with enhanced flexibility but creates questions about the respective advantages, limitations and indications for each system. A good understanding of the different flow rate settings is essential for the surgeon and can lead to safer procedures.

The purpose of this study was to analyze the influence of different cut rates and aspiration levels with three distinct sizes of cutters on the flow rate performance of ultra high-speed cutters operated with a commercially available dual pneumatic vitrectomy system.

\section{Materials and Methods}

Performance of the 20-, 23- and 25-gauge cutters (three cutters for each gauge) was tested using the Constellation Vision System (Alcon Labs Inc., Fort Worth, Tex. USA) with the standard duty cycle setting of the machine (maximum port open time achieved at each cut rate).

Duty cycle was evaluated using a stop-action camera (Motionscope M1, Red Lake, Tokyo, Japan) with resolution of 1,000 frames per second in order to a capture a high-speed video of the cutter action. Frame-by-frame analysis of the video was used to determine duty cycle as a function of speed. Two masked investigators independently analyzed the frames to determine the cutting phases (completely open, opening, closing, and closed) of the system standard duty cycle. Opening time was defined as the time between the first frame of guillotine opening and the last frame of guillotine disappearance. Open time was measured between the end of opening time and the start of closing time. Closing time was defined as when the guillotine reappeared through the cutting port until it was completely closed. Closed time started from the end of closing time and ended at the start of opening time. The final duty cycle was generated by the equation: duty cycle $=[$ open time $+1 / 2$ (opening time + closing time) $] /$ cycle duration.

For flow rate tests, each cutter was suspended in a vial of either water or porcine vitreous fluid. The vitreous fluid used for the experiments was carefully removed en bloc from porcine eyes

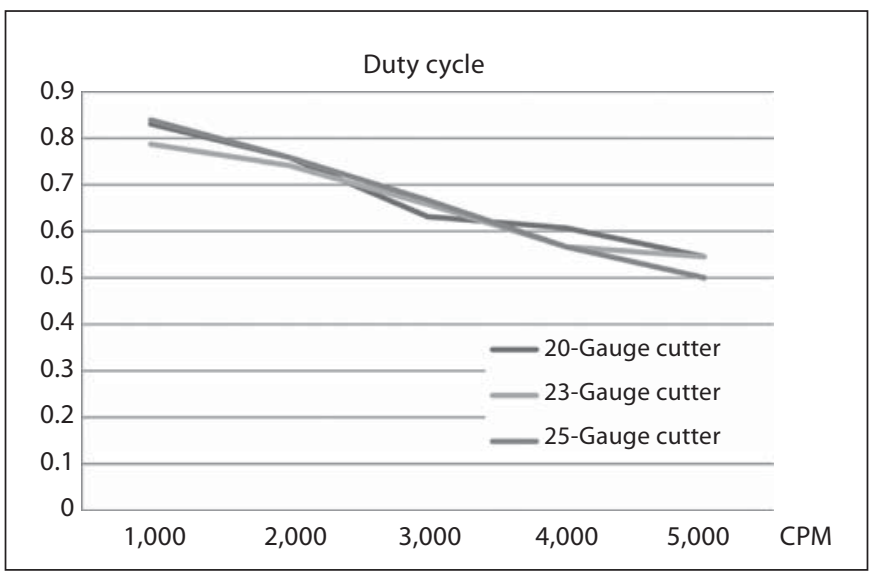

Fig. 1. Duty cycle of 20-, 23- and 25-gauge cutters. For all three gauges, the standard duty cycle peaked at 1,000 CPM and dropped as the cut rate increased.

enucleated less than $12 \mathrm{~h}$ postmortem. All eyes were kept at $4^{\circ} \mathrm{C}$ before use.

The vials were placed on a precision $(0.01 \mathrm{~g})$ balance (Ohaus Corp. Parsippany, N.J., USA) that continually measured the weight of remaining water or vitreous fluid throughout each trial. Using a high-sampling (2 samples/s) data acquisition software (LabVIEW, National Instruments, Austin, Tex., USA), the remaining mass was recorded in real time and results were converted to volume removed as a function of time - flow rate $(\mathrm{ml} / \mathrm{s})$. The density of the porcine vitreous fluid was assumed to be approximately equal to the density of water $(\mathrm{d}=1 \mathrm{~g} / \mathrm{ml})$. Thirty-six experiments were conducted for each cutter at different cut rates [0 (only for water), 1,000, 2,000, 3,000, 4,000 and 5,000 CPM] and aspiration levels $(100,200,300,400,500$ and $600 \mathrm{~mm} \mathrm{Hg})$ in both water and vitreous fluid. A total of 300 measurements were taken for water and 600 measurements for vitreous fluid in each experiment.

The average and standard deviation of water and vitreous flow rate were calculated for each size (gauge), aspiration level and cut rate. Repeated measures of variance analysis tested the mean water and vitreous flow rates between aspiration and cut rates. Mixed models with repeated measures were used to obtain regression equations to predict mean water and vitreous flow rates. Average flow rate differences among the three different gauges analyzed were calculated by repeated measures analysis of covariance. SAS version 9.1 programming language (SAS Institute Inc., Cary, N.C., USA) was used for all analyses. The accepted level of significance for all tests was a $\mathrm{p}$ value of $<0.05$.

\section{Results}

\section{Duty Cycle for 20-, 23- and 25-Gauge Cutters}

For 20-, 23- and 25-gauge cutters analyzed, standard duty cycle peaked at 1,000 CPM and dropped linearly as the cut rate increased, ranging from 83 to $54 \%$ for 
Table 1. Multiple regression models using mixed repeated measure models, predicting vitreous and water flow rates for increasing aspiration and cut rates

\begin{tabular}{|c|c|c|}
\hline & Parameter estimate, $\mathrm{ml} / \mathrm{s}$ & $\mathrm{p}$ value \\
\hline \multicolumn{3}{|l|}{ Vitreous flow rates } \\
\hline \multicolumn{3}{|l|}{20 -gauge cutter, $\mathrm{R}^{2}=0.89$} \\
\hline Intercept & $-0.03076(0.005556)$ & \\
\hline Aspiration (per $100 \mathrm{~mm} \mathrm{Hg}$ increase) & $0.02138(0.000723)$ & $<0.001$ \\
\hline CPM (per 1,000 increase) & $0.00738(0.001491)$ & $<0.001$ \\
\hline \multicolumn{3}{|l|}{23 -gauge cutter, $\mathrm{R}^{2}=0.91$} \\
\hline Intercept & $-0.01461(0.002029)$ & \\
\hline Aspiration (per $100 \mathrm{~mm} \mathrm{Hg}$ increase) & $0.008873(0.000270)$ & $<0.001$ \\
\hline CPM (per 1,000 increase) & $0.003703(0.000541)$ & $<0.001$ \\
\hline \multicolumn{3}{|l|}{25 -gauge cutter, $\mathrm{R}^{2}=0.79$} \\
\hline Intercept & $-0.00812(0.001497)$ & \\
\hline Aspiration (per $100 \mathrm{~mm} \mathrm{Hg}$ increase) & $0.004814(0.000274)$ & $<0.001$ \\
\hline CPM (per 1,000 increase) & $0.002244(0.000347)$ & $<0.001$ \\
\hline \multicolumn{3}{|l|}{ Water flow rates } \\
\hline \multicolumn{3}{|l|}{20 -gauge cutter, $\mathrm{R}^{2}=0.89$} \\
\hline Intercept & $0.2017(0.02199)$ & \\
\hline Aspiration (per $100 \mathrm{~mm} \mathrm{Hg}$ increase) & $0.09181(0.002820)$ & $<0.001$ \\
\hline CPM (per 1,000 increase) & $-0.06349(0.006489)$ & $<0.001$ \\
\hline \multicolumn{3}{|l|}{23 -gauge cutter, $\mathrm{R}^{2}=0.94$} \\
\hline Intercept & $0.07127(0.006276)$ & \\
\hline Aspiration (per $100 \mathrm{~mm} \mathrm{Hg}$ increase) & $0.04177(0.001070)$ & $<0.001$ \\
\hline CPM (per 1,000 increase) & $-0.02402(0.001664)$ & $<0.001$ \\
\hline \multicolumn{3}{|l|}{25 -gauge cutter, $\mathrm{R}^{2}=0.87$} \\
\hline Intercept & $0.03659(0.007303)$ & \\
\hline Aspiration (per $100 \mathrm{~mm} \mathrm{Hg}$ increase) & $0.02964(0.000709)$ & $<0.001$ \\
\hline CPM (per 1,000 increase) & $-0.00936(0.002268)$ & $<0.001$ \\
\hline
\end{tabular}

Values in parentheses are standard errors. $\mathrm{R}^{2}=$ Coefficient of determination.

20 -gauge, from 78 to $54 \%$ for 23 -gauge and from 83 to $50 \%$ for 25 -gauge cutters (fig. 1). Incomplete port closing and opening was not observed for any of the three gauges using independent analysis of high-speed video results.

\section{Water Flow for 20-, 23- and 25-Gauge Cutters}

The water flow rate for 20-, 23- and 25-gauge cutters at various cut rates and different aspiration levels is depicted in figure 2. Water flow rates for all sizes of cutters increased with aspiration levels, peaking at 0 CPM and dropped with increasing cut rate. This trend was significant at all tested aspiration levels ( $\mathrm{p}<0.05$, except for the 25-gauge cutter at $100 \mathrm{~mm} \mathrm{Hg}$ aspiration).

The water flow rate for the 20-gauge cutter increased proportionally $0.091 \mathrm{ml} / \mathrm{s}$ for every $100 \mathrm{~mm} \mathrm{Hg}$ increase in aspiration level and decreased proportionately 0.063 $\mathrm{ml} / \mathrm{s}$ for every 1,000 CPM increase. For the 23 -gauge cutters, flow increased proportionately $0.041 \mathrm{ml} / \mathrm{s}$ for every
$100 \mathrm{~mm} \mathrm{Hg}$ increase in aspiration level and decreased proportionately $0.024 \mathrm{ml} / \mathrm{s}$ for every 1,000 CPM increase. For the 25-gauge cutters, flow increased proportionately $0.029 \mathrm{ml} / \mathrm{s}$ for every $100 \mathrm{~mm} \mathrm{Hg}$ increase in aspiration level and decreased proportionately $0.009 \mathrm{ml} / \mathrm{s}$ for every 1,000 CPM increase ( $p<0.001$ for all). The coefficient of determination of this water flow model varied from 0.87 to 0.94 (table 1).

\section{Vitreous Flow for 20-, 23- and 25-Gauge Cutters}

Vitreous flow rates for 20-, 23- and 25-gauge cutters at various cut rates and different aspiration levels are depicted in figure 2 . The flow was significantly higher when using larger gauges ( $p<0.001$; table 2$)$. Vitreous flow rates for 20-, 23- and 25-gauge cutters increased with increasing aspiration and cut rates $(\mathrm{p}<0.05)$

Vitreous flow for the 20-gauge cutter increased proportionately $0.021 \mathrm{ml} / \mathrm{s}$ for every $100 \mathrm{~mm} \mathrm{Hg}$ increase in 


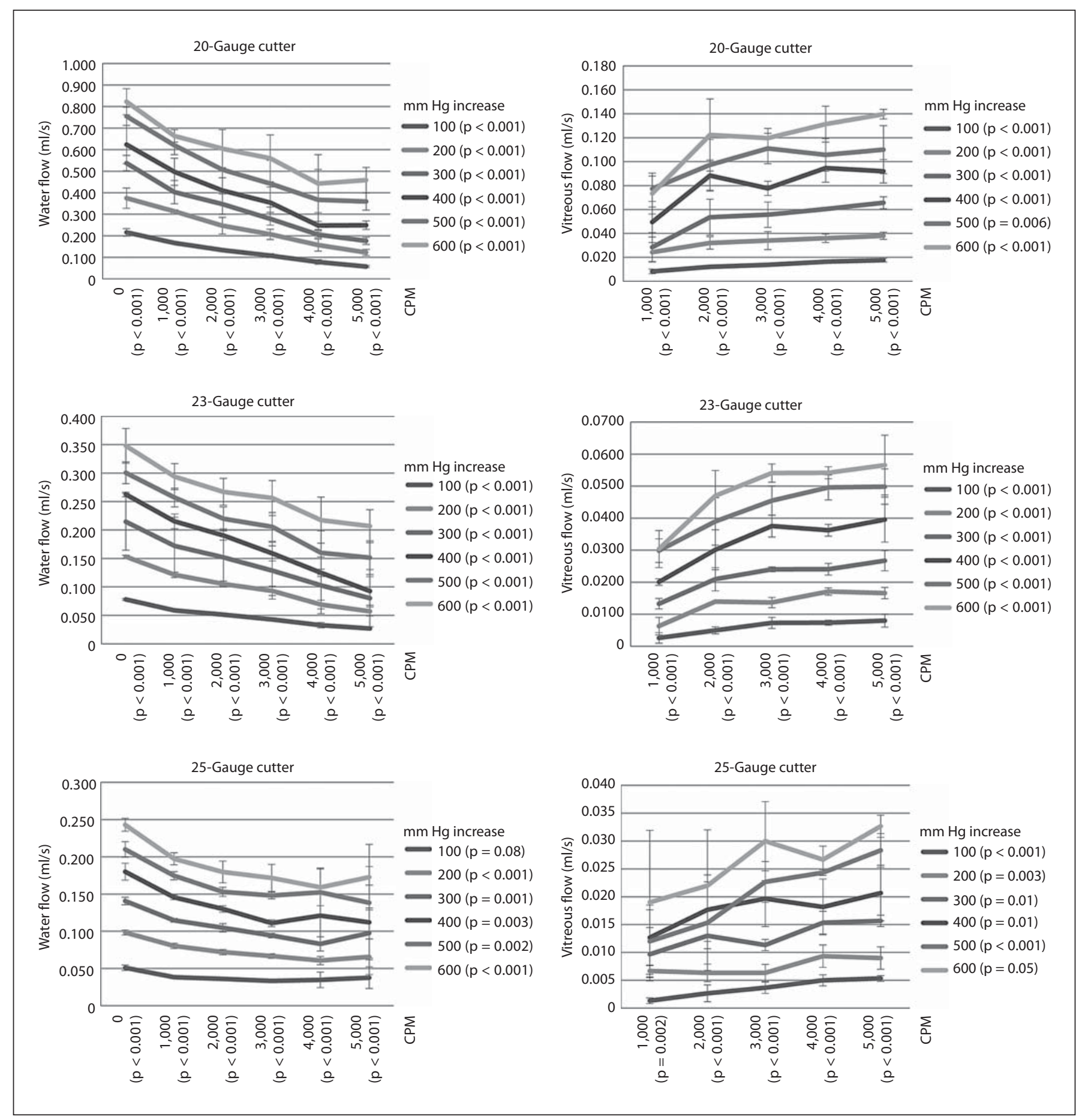

Fig. 2. Water and vitreous flow rates of 20-, 23 - and 25-gauge cutters (mean \pm standard deviation). p values represent the analysis of variance by aspiration (vertical axis) and the cut rate (horizontal axis). Water flow rates for all sizes of cutters increased with the aspiration levels, peaked at 0 CPM and dropped with increasing cut rate. Vitreous flow rates for all gauge cutters increased with increasing aspiration and cut rates. 
Table 2. Average flow rate differences among different gauges, adjusting for aspiration and cut rate

$$
\begin{aligned}
& \text { Least square means } \text { p value }^{1} \\
& \pm \mathrm{SE}, \mathrm{ml} / \mathrm{s}
\end{aligned}
$$

Vitreous flow rates

20-gauge cutter $\quad 0.0662 \pm 0.0024$

23-gauge cutter $\quad 0.0275 \pm 0.0008$

25 -gauge cutter $\quad 0.0155 \pm 0.0009$

20- vs. 23-gauge cutter $<0.0001$

20 - vs. 25-gauge cutter $<0.0001$

$0.0155 \pm 0.0009-23$ - vs. 25 -gauge cutter $<0.0001$

Water flow rates

20 -gauge cutter $\quad 0.3643 \pm 0.0167$

23-gauge cutter $\quad 0.1574 \pm 0.0044$

25 -gauge cutter $\quad 0.1169 \pm 0.0100$

20- vs. 23-gauge cutter $<0.0001$

20- vs. 25-gauge cutter $<0.0001$

23- vs. 25-gauge cutter $<0.0001$

\footnotetext{
${ }^{1}$ Repeated measures analysis of covariance. $\mathrm{SE}=$ Standard error.
}

aspiration level and increased proportionately $0.007 \mathrm{ml} / \mathrm{s}$ for every 1,000 CPM increase. For the 23-gauge cutters, flow increased proportionately $0.008 \mathrm{ml} / \mathrm{s}$ for every 100 $\mathrm{mm} \mathrm{Hg}$ increase in aspiration level and increased proportionately $0.003 \mathrm{ml} / \mathrm{s}$ for every 1,000 CPM increase. For the 25 -gauge cutters, flow increased proportionately 0.004 $\mathrm{ml} / \mathrm{s}$ for every $100 \mathrm{~mm} \mathrm{Hg}$ increase in aspiration level and increased proportionately $0.002 \mathrm{ml} / \mathrm{s}$ for every 1,000 CPM increase $(p<0.001$ for all). The coefficient of determination of this vitreous flow model varied from 0.79 to 0.91 (table 1).

\section{Discussion}

During vitrectomy surgery, fluidics inflow has to be equal to outflow in order to maintain stability and avoid intraocular complications. At least 10 physical and independent factors influence the outflow rates: (1) viscosity of the aspirated fluid; (2) inner diameter of the vitrectomy probe; (3) size of the fragmented vitreous; (4) turbulence of the fluid inside and outside of the probe and aspiration tube; (5) size of the cutting port; (6) length of the aspiration tube; (7) structure of the instruments; (8) aspiration level; (9) cut rate, and (10) duty cycle [6,7]. Viscosity of aspirated vitreous fluid depends on the initial viscosity of the gel, change in viscosity induced by the fragmentation action of the vitrectomy probe, and the resistance of the fluid inside of the aspiration tube [12]. While water is readily aspirated, vitreous fluid requires cutting in small pieces before the final aspiration.

Water flow rate curves were similar to the duty cycle curves, peaking at $0 \mathrm{CPM}$ and decreasing linearly with increasing cut rates. As cut rate increases, duty cycle reduces to some degree and flow rates become disproportionally lower. In conventional cutters, duty cycle can decrease to $6.3 \%$ at high cut rates [9]. Although it is known that pneumatic cutters with spring return systems are limited in controlling the duty cycle, it has been reported that the duty cycle could be maintained up to $63 \%$ at 2,500 in one of those cutters [7]. In this experiment, the dual pneumatic ultra high-speed system maintains a relatively high duty cycle, even at higher cut rates for all sizes of vitreous probe (50-54\% of duty cycle at 5,000 CPM among the three gauges tested).

Changes in aspiration and cut rate were responsible for 79-91\% of the vitreous flow rate variability in this regression model analysis. Vitreous flow rates showed an increasing trend for all gauges tested, with increasing aspiration and cut rates. Vitreous fluid is classified as a semisolid mixture of water, collagen fibers and hyaluronic acid and contains pieces that can obstruct the cutter port and increase resistance of flow inside of the tube [4]. At high cut rates, smaller pieces are less resistant to aspiration and flow is increased [7]. Additionally, a smaller vitreous piece lowers the traction on the vitreous body $[8$, 13]. This physical property would be beneficial for two main situations of vitreous removal: (1) core vitrectomy, where higher aspiration is useful, and (2) vitreous shaving, where lower flows are required. Experimental studies have shown that vitreoretinal traction decreases with increasing cut rates (up to 2,500 CPM), but no ultra highspeed cutters have been studied [13]. Clinically, the use of high cut rates $(5,000 \mathrm{CPM})$ has shown benefits in terms of duration of vitrectomy time and incidence of iatrogenic retinal breaks [14].

New developments aim to increase surgical precision and thus improve safety and efficacy of vitreoretinal surgery. Transconjunctival vitrectomy systems have greatly improved patient comfort and has allowed for faster postoperative recovery [15]. However, small-gauge technique can present some disadvantages, especially in complicated cases where extensive manipulation is required. Smaller-gauge vitrectomy probes are more flexible and may result in difficulties when used to rotate the eye for removal of peripheral vitreous fluid [16]. Also, small-gauge vitrectomy instruments require higher aspiration to cre- 
ate a posterior vitreous detachment and to achieve a reasonable rate of vitreous fluid removal [11]. Knowing these differences helps the surgeon decide which cases are suitable for small-gauge vitrectomy versus those that can be performed more easily with 20 -gauge instrumentation. The current study demonstrated that although higher cut rates increase the vitreous flow in all probe sizes, the 20 -gauge cutter removed more vitreous fluid when compared to smaller gauges. For example, when comparing the flow at 5,000 CPM, the 20-gauge cutter was able to remove $2.25-2.45 \times(100-600 \mathrm{~mm} \mathrm{Hg})$ more vitreous fluid than the 23-gauge cutter and 3.6-4.11 $\times$ more than the 25 -gauge cutters; the 23 -gauge cutter is able to remove $1.6-1.67 \times$ more vitreous fluid than the 25 -gauge, using the same parameters. 20-Gauge vitrectomy remains in use to facilitate complicated surgeries due to the possibility of higher flow rates, stiffness of the vitrectomy probe and the greater array of instruments available (picks, scissors, forceps, phacofragmenters).

In summary, flow rates from the dual pneumatic system are stable and predictable for all sizes of cutters tested. Larger size of the cutters, as well as higher aspiration and cut rate levels resulted in improvement of vitreous flow rates. Although under real surgical conditions, heterogeneous composition of fluid makes fluid dynamics less predictable, these findings should help the surgeon in selecting the optimal outflow parameters to carry out a safe and effective surgery.

\section{Acknowledgements}

This study was supported in part by the Eye Concepts Laboratory at the Doheny Eye Institute, National Eye Institute basic research grant (EY03040), the CAPES Foundation - Brazil [BEX 2326-11-6 (BD)], CNPq (the National Council of Research - Brazil) and an unrestricted grant from Research to Prevent Blindness. We thank Laurie Dustin for the statistical analysis and Susan Clarke for the text review.

\section{Disclosure Statement}

No financial relationship with the organizations that sponsored the research exists. The authors have no proprietary or commercial interest in any of the materials discussed in this article.

\section{References}

1 Hubschman JP, Bourges JL, Tsui I, Reddy S, Yu F, Schwartz SD: Effect of cutting phases on flow rate in 20-, 23-, and 25-gauge vitreous cutters. Retina 2009;29:1289-1293.

$\checkmark 2$ Charles S: An engineering approach to vitreoretinal surgery. Retina 2004;24:435-444.

3 Magalhaes O Jr, Chong L, DeBoer C, Bhadri P, Kerns R, Barnes A, Fang S, Humayun M: Vitreous dynamics: vitreous flow analysis in 20-, 23-, and 25-gauge cutters. Retina 2008; 28:236-241.

4 Magalhaes O Jr, Maia M, Rodrigues EB, Machado L, Costa EF, Maia A, Moraes-Filho MN, Dib E, Farah ME: Perspective on fluid and solid dynamics in different pars plana vitrectomy systems. Am J Ophthalmol 2011; 151:401-405.

5 Magalhaes O Jr, Chong L, DeBoer C, Bhadri P, Kerns R, Barnes A, Fang S, Schor P, Humayun M: Guillotine performance: duty cycle analysis of vitrectomy systems. Retin Cases Brief Rep 2009;3:64-67.
-6 Sato T, Kusaka S, Oshima Y, Fujikado T: Analyses of cutting and aspirating properties of vitreous cutters with high-speed camera. Retina 2008;28:749-754.

7 Matsuoka N, Teixeira A, Lue JC, Fang S, Kerns R, Bhadri P, Humayun M: Performance analysis of millennium vitreous enhancer system. Ophthalmic Surg Lasers Imaging 2011;42:162-167.

$\checkmark 8$ Steel DH, Charles S: Vitrectomy fluidics. Ophthalmologica 2011;226:27-35.

-9 Fang SY, DeBoer CM, Humayun MS: Performance analysis of new-generation vitreous cutters. Graefes Arch Clin Exp Ophthalmol 2008;246:61-67.

10 Yanyali A, Celik E, Horozoglu F, Oner S, Nohutcu AF: 25-Gauge transconjunctival sutureless pars plana vitrectomy. Eur J Ophthalmol 2006;16:141-147.

-11 Thompson JT: Advantages and limitations of small gauge vitrectomy. Surv Ophthalmol 2011;56:162-172.

12 Hubschman JP, Gupta A, Bourla DH, Culjat M, Yu F, Schwartz SD: 20-, 23-, and 25-gauge vitreous cutters: performance and characteristics evaluation. Retina 2008;28:249-257.
13 Teixeira A, Chong LP, Matsuoka N, Arana L, Kerns R, Bhadri P, Humayun M: Vitreoretinal traction created by conventional cutters during vitrectomy. Ophthalmology 2010; 117:1387-1392.

14 Rizzo S, Genovesi-Ebert F, Belting C: Comparative study between a standard 25-gauge vitrectomy system and a new ultrahighspeed 25-gauge system with duty cycle control in the treatment of various vitreoretinal diseases. Retina 2011;31:2007-2013.

15 Fujii GY, De Juan E Jr, Humayun MS, Pieramici DJ, Chang TS, Awh C, Ng E, Barnes A, Wu SL, Sommerville DN: A new 25 -gauge instrument system for transconjunctival sutureless vitrectomy surgery. Ophthalmology 2002;109:1807-1812.

16 Williams GA: 25-, 23-, or 20-gauge instrumentation for vitreous surgery? Eye 2008;22: 1263-1266. 